\title{
Effects of a lifestyle intervention on endothelial function in men on long-term androgen deprivation therapy for prostate
} cancer

\author{
Stephen E Gilbert ${ }^{1}$, Garry A Tew ${ }^{2}$, Caroline Fairhurst ${ }^{3}$, Liam Bourke ${ }^{4}$, John M Saxton ${ }^{2}$, Edward M Winter ${ }^{4}$ \\ and Derek J Rosario*,5 \\ ${ }^{1}$ Faculty of Health and Life Sciences, York St John University, Lord Mayor's Walk, York YO31 7EX, UK; ${ }^{2}$ Department of Sport, \\ Exercise and Rehabilitation, Faculty of Health and Life Sciences, Northumbria University, Newcastle Upon Tyne NE1 8ST, UK; ${ }^{3}$ York \\ Trials Unit, Department of Health Sciences, University of York, York YO10 5DD, UK; ${ }^{4}$ Centre for Sport and Exercise Science, \\ Sheffield Hallam University, Collegiate Crescent, Sheffield S10 2BP, UK and ${ }^{5}$ Academic Urology Unit, Department of Oncology, \\ Royal Hallamshire Hospital, University of Sheffield, Sheffield S11 7FE, UK
}

Background: Treatment of prostate cancer with androgen deprivation therapy (ADT) is associated with metabolic changes that have been linked to an increase in cardiovascular risk.

Methods: This randomised controlled trial investigated the effects of a 12-week lifestyle intervention that included supervised exercise training and dietary advice on markers of cardiovascular risk in 50 men on long-term ADT recruited to an on-going study investigating the effects of such a lifestyle intervention on quality of life. Participants were randomly allocated to receive the intervention or usual care. Cardiovascular outcomes included endothelial function (flow-mediated dilatation (FMD) of the brachial artery), blood pressure, body composition and serum lipids. Additional outcomes included treadmill walk time and exercise and dietary behaviours. Outcomes were assessed before randomisation (baseline), and 6, 12 and 24 weeks after randomisation.

Results: At 12 weeks, the difference in mean relative FMD was $2.2 \%$ (95\% confidence interval $(\mathrm{Cl}) 0.1-4.3, P=0.04)$ with an effect size of $0.60(95 \% \mathrm{Cl}<0.01-1.18)$ favouring the intervention group. Improvements in skeletal muscle mass, treadmill walk time and exercise behaviour also occurred in the intervention group over that duration $(P<0.05)$. At 24 weeks, only the difference in treadmill walk time was maintained.

Conclusions: This study demonstrates that lifestyle changes can improve endothelial function in men on long-term ADT for prostate cancer. The implications for cardiovascular health need further investigation in larger studies over longer duration.

Treatment with androgen deprivation therapy (ADT) has established benefits for men with locally advanced or metastatic prostate cancer (Schubert et al, 2012), but has been associated with the development of adverse events that can impact physical and mental well being (Nguyen et al, 2015). Evidence of metabolic complications of $\mathrm{ADT}$ that lead to increased cardiovascular risk is accumulating (Zhao et al, 2014). Increased incidences of abdominal adiposity, insulin resistance, hyperglycaemia and hyperlipidaemia have been reported in men on such treatment (Nguyen et al, 2015).

An increase in cardiovascular risk factors through the development of metabolic complications to long-term ADT has been

*Correspondence: DJ Rosario; Email: d.j.rosario@sheffield.ac.uk.

Received 15 June 2015; revised 3 December 2015; accepted 8 December 2015; published online 14 January 2016

(c) 2016 Cancer Research UK. All rights reserved 0007 - 0920/16 
supported by evidence of a reduction in flow-mediated dilatation (FMD) of the brachial artery in men treated with long-term ADT (Gilbert et al, 2013). Reduced FMD indicates endothelial dysfunction (Deanfield et al, 2007), which is regarded as an important early stage in the development of atherosclerosis (Celermajer, 1997). Endothelial function, as measured by brachial artery FMD, is also an established predictor of future cardiovascular events (Ras et al, 2013).

The traditional approach for presenting the results of FMD has been in the form of absolute change in arterial diameter after release of cuff occlusion or a simple ratio of the change of arterial diameter over the resting arterial diameter, so-called relative FMD (Gokce et al, 2002; Edwards et al, 2004; Green et al, 2011). Concerns have been expressed as to the appropriateness of simple ratio standards for such physiological variables, with allometric scaling being deemed to be both biologically and mathematically superior (Tanner, 1949; Packard and Boardman, 1999; Curran-Everett, 2013). More recently, the validity of this approach has been demonstrated for FMD data (Atkinson and Batterham, 2013; Atkinson et al, 2013).

Given the established benefits of exercise and dietary changes to cardiovascular health in other patient groups (Rippe and Angelopoulos, 2014), we hypothesised that a supervised exercise training and dietary advice intervention would result in a reduction in cardiovascular risk factors in sedentary men on ADT. We tested this hypothesis in a randomised controlled trial and report the results herein.

\section{MATERIALS AND METHODS}

During the course of a randomised controlled trial investigating the effects of a lifestyle intervention on quality of life in men with prostate cancer on ADT (trial registration number ISRCTN88605738), a protocol amendment was approved by the Yorkshire and Humber NHS Research Ethics Committee to commence the collection of additional measures of cardiovascular risk.

The patient population and intervention for the full trial have been described in detail previously (Bourke et al, 2014). Here we present results for the subset of men recruited after the amendment was implemented.

Sample size. A sample size of 50 men was deemed sufficient to detect an absolute difference in relative brachial artery FMD of $2.6 \%$; a difference reported in exercise studies in elderly patients at increased cardiovascular risk (Gokce et al, 2002; Edwards et al, 2004). This sample size assumed a s.d. of 3\%, an alpha of $0.05,80 \%$ power and 10\% attrition (Bourke et al, 2011).

Randomisation. Participants were randomised $1: 1$ to receive 12 weeks of supervised exercise training and dietary advice in addition to usual care or to receive usual care alone. A randomly ordered list of group allocation was generated at study commencement using the nQuery Statistical Software (nQuery Advisor 6.01, nQuery Statistical Solution, USA). Neither the researchers nor the participants were informed of treatment allocation until completion of baseline assessments.

Intervention and usual care. Participants were prescribed three exercise sessions per week, tapering the supervision over the intervention (2:1 supervised to home based in weeks 1-6 and $1: 2$ in weeks $7-12)$. An experienced exercise physiologist led supervised sessions that lasted $\sim 1 \mathrm{~h}$ and consisted of a mixture of aerobic, resistance and balance exercises. Aerobic exercise was $30 \mathrm{~min}$ at $55-75 \%$ of age-predicted maximum heart rate or $11-13$ on the Borg Rating of Perceived Exertion (RPE) scale (Borg, 1982) using stationary cycles, rowing ergometers and treadmills.
Resistance exercises were performed for two to four sets of 8-12 repetitions beginning at an intensity of $60 \%$ of one repetition maximum and progressed through increasing volume before weight was increased. Advice on suitable exercises to perform at home for a minimum of 30 min was provided (e.g., brisk walking, cycling and gym exercise). Participants were instructed how to monitor intensity using RPE.

Small-group healthy-eating seminars led by the exercise physiologist, lasting $\sim 20 \mathrm{~min}$, were delivered every 2 weeks throughout the intervention. Advice included: reduction in dietary fat intake to $\sim 25 \%$ of total energy intake, consumption of at least five portions of fruit and vegetables each day, increased fibre consumption, decreased intake of refined carbohydrates and limiting alcohol intake to 1-2 units per day.

The control participants were men randomised to usual care who were followed up in the urology clinic as per usual clinical protocol. No restrictions were placed on them in relation to exercise or dietary behaviours over the period of the study.

Outcome measures. The primary outcome was brachial artery FMD (endothelium-dependent arterial dilatation) expressed as the percentage change in arterial diameter at 12 weeks. Secondary outcomes include glyceryl trinitrate (GTN)-mediated brachial artery dilatation (endothelium-independent arterial dilatation), resting blood pressure, treadmill walk time, body mass and composition, lipid profile, biomarkers of disease status, physical activity and dietary behaviours. Outcome measures were assessed at baseline, at 6 and 12 weeks of the intervention and at 24 weeks (12 weeks after cessation of the intervention).

Vascular assessments. Ultrasound assessments of the right brachial artery were performed while the participant rested supine. All assessments were undertaken by one researcher (coefficient of variation for repeated FMD measures 10.97\%) using a $7-\mathrm{mHz}$ linear array transducer attached to a high-frequency ultrasound system (Terason T3000, Teratech Corporation, Burlington, MA, USA). Participants rested quietly for a minimum of $15 \mathrm{~min}$ before commencing assessments.

For FMD assessments, a pneumatic rapid inflation/deflation cuff (Hokanson E20 cuff, D.E. Hokanson Inc, Bellevue, WA, USA) was placed distal to the olecranon process, with arterial imaging performed in the distal third of the upper arm. Resting measurement of vessel diameter was performed for $1 \mathrm{~min}$ before cuff inflation to a pressure $50 \mathrm{~mm} \mathrm{Hg}$ above systolic blood pressure. Occlusion was maintained for 5 min. Recordings were restarted $30 \mathrm{~s}$ before cuff release and continued for a further $3 \mathrm{~min}$ thereafter (Black et al, 2008).

After 15 min rest following FMD assessments, GTN-mediated brachial artery dilatation was assessed. Arterial imaging was performed for $1 \mathrm{~min}$ before administration of a sublingual dose $(0.4 \mathrm{mg})$ of GTN, and continued for a further $6 \mathrm{~min}$ thereafter (Corretti et al, 2002) with recording maintained throughout.

The ultrasound on-screen display was recorded at a rate of $15 \mathrm{~Hz}$ (Camtasia Studio software, v5.0.0, TechSmith Corporation, Okemos, MI, USA). Subsequently, analysis was undertaken using the Brachial Analyser for Research software package (v5.6.19, Medical Imaging Applications, Iowa, USA). All scans were analysed in full by a researcher external to the research team who was blinded to participant group allocation.

Raw data for arterial diameter were smoothed before determination of the magnitude of arterial dilatation using the same method as previously described (Black et al, 2008). Arterial data are displayed as the absolute (millimetres) and relative (percentage) change in arterial diameter from resting arterial diameter $\left(D_{\text {rest }}\right)$ to peak arterial diameter $\left(D_{\text {peak }}\right)$. For analysis, data were allometrically scaled (Atkinson et al, 2013). Arterial shear rate (SR) for FMD assessments was calculated using the equation $\mathrm{SR}=4 \times V / D$, 
where $V$ is Doppler velocity and $D$ is vessel diameter (Parker et al, 2009). Shear rate area under the curve was calculated as the sum of arterial shear from cuff release through to $D_{\text {peak }}$.

Anthropometry. Stature (Holtain Stadiometer, Holtain Ltd, Pembrokeshire, UK) and body mass (Weylux Beam Balance Scales, Weylux, UK) were assessed using standard laboratory techniques to $0.1 \mathrm{~cm}$ and $0.05 \mathrm{~kg}$, respectively, and body mass index (BMI) was calculated. Body composition was assessed via bioelectrical impedance (Inbody 720, Biospace, Seoul, South Korea).

Resting blood pressure. Resting blood pressure and heart rate were assessed in the left arm with an automated sphygmomanometer (Dinamap, Dash 2500, GE Healthcare, Waukesha, WI, USA) while participants rested supine before FMD assessments.

Exercise tolerance. A sub-maximal walking test was performed on a treadmill (H/P/ Cosmos Pulsar Treadmill, Traunstein, Germany) using the BSU/Bruce protocol (Kaminsky and Whaley, 1998). Participants were given time walking on a treadmill before the test to allow them to become comfortable with treadmill use. A chest-strap heart rate monitor (Polar F4, Polar Electro, Kempele, Finland) was fitted and participants were accustomed to the 6-20 Borg scale (Borg, 1982). Heart rate and RPE were recorded at the end of every minute of exercise. The test ended when participants achieved an RPE of 15 ('Hard') or earlier if the participant requested to stop. Treadmill tests were conducted by a researcher external to the research team who was blinded to participant group allocation.

Blood markers. A fasting blood sample $(20 \mathrm{ml})$ was drawn from the antecubital vein using standard venepuncture techniques. Samples were analysed in duplicate in the Department of Clinical Chemistry at the Royal Hallamshire Hospital, Sheffield, UK, for blood lipid profile (total cholesterol, HDL-C, LDL-C and triglycerides), prostate-specific antigen and male sex hormones (testosterone, SHBG). In addition, free androgen index was calculated.

Exercise and dietary behaviour. Leisure time physical activity was quantified using the Godin Leisure Score Index (LSI; Godin and Shephard, 1985). A higher score indicated more activity. The Godin LSI has been successfully used with men on ADT (Culos-Reed et al, 2010).

Participants completed 3-day diet diaries at baseline, 12 and 24 weeks. Where possible, participants were asked to use the same 3 days of the week for each assessment. Nutritional data were analysed using NetWisp (version 3.0, Tinuviel Software, Anglesey, UK).

Statistical analysis. Analyses were performed in Stata v13 on an intention-to-treat basis including all available participants in the groups to which they were randomised, using two-sided significance at the 5\% level. Treatment effects are presented as the difference in adjusted means (intervention minus control) and Hedge's g effect sizes with $95 \%$ confidence intervals (CIs) and $P$-values.

Arterial diameter data (FMD- and GTN-mediated dilatation) were allometrically scaled and analysed as follows. The difference between logarithmically transformed $D_{\text {rest }}$ and $D_{\text {peak }}$ was calculated for each participant and time point, and then analysed using a covariance pattern mixed model, with treatment group, time and a treatment group-by-time interaction as fixed factors, and $\log D_{\text {rest }}$ as a time-varying covariate. Means for diameter change on the logged scale for each treatment group and time point were obtained and then back transformed by antilogging to provide an adjusted ratio of $D_{\text {peak }} / D_{\text {rest }}$, subtracting a value of 1 and multiplying by 100 to provide a $D_{\text {rest }}$ adjusted estimate of relative FMD. An estimate for the s.d. was obtained by multiplying the s.e. of the mean diameter change by the square root of the sample size, antilogging, subtracting 1 and multiplying by 100 . Estimates for the difference in mean diameter change between the treatment groups at each time point were extracted from the model with $95 \%$ CIs and $P$-values. The $P$-values are presented unchanged in this paper, but the point and interval estimates were transformed as described above.

To allow comparison of the results with previous publications using a simple ratio only, the difference in (simple ratio) relative FMD between the trial arms at 12 weeks was extracted from a single linear covariance pattern mixed model in which relative FMD at each time point was nested within patients (Brown and Prescott, 2006). Relative FMD at baseline, each time point of follow-up, trial arm and a time-by-trial arm interaction were included in the model. The estimates of the treatment effect at 6 and 24 weeks were extracted for secondary investigations. Estimation was based on the method of restricted maximum likelihood (Harville, 1977).

The following outcomes were analysed in the same way as (simple ratio) relative FMD: absolute FMD, relative GTN-mediated dilatation, absolute GTN-mediated dilatation dilation, systolic and diastolic blood pressure, BMI and treadmill walk time.

All other secondary outcomes were compared between the treatment groups at 12 weeks using ANCOVA to adjust for the baseline value. No adjustment for multiple testing was made.

\section{RESULTS}

This analysis is of 50 men (mean age 70 years-range 53-84 years) consecutively recruited to the latter part of the primary trial (Bourke et al, 2014) with 25 randomised to each trial arm (Figure 1). The median time on ADT at recruitment was 19 and 18 months in the intervention and control groups, respectively. The groups were comparable at baseline with the exception of previous radiotherapy exposure (Table 1 ).

There were seven withdrawals (three in the intervention and four in the control group) and one death (control group) before the end of the 12-week intervention. There was one additional withdrawal and death (both intervention group) before the 24-week assessment. Both deaths were considered unrelated to the study intervention. For men completing the 12-week intervention, adherence to supervised sessions was 93\% (368 out of 396 possible) and to home-based sessions was 76\% (301 out of 396 completed), respectively.

At 12 weeks, the difference in allometrically scaled relative FMD was $2.2 \%$ (95\% CI $0.1-4.3, P=0.04$, Hedge's g $0.60,95 \%$ CI $<0.01-1.18$ ) favouring the intervention group (Table 2). The difference in absolute FMD was $0.11 \mathrm{~mm}$ (95\% CI $<0.01-0.23$, $P=0.05$, Hedge's g $0.59,95 \% \mathrm{CI}-0.01$ to 1.17$)$. This benefit was not maintained at 24 weeks $(0.31$ s.d., $95 \%$ CI -0.27 to 0.88 for allometrically scaled relative FMD and 0.31 s.d., $95 \% \mathrm{CI}-0.27$ to 0.89 for absolute FMD). The results for the non-scaled simple ratio FMD are presented alongside the scaled results in Table 2.

There was no meaningful difference in GTN-mediated dilatation (absolute or relative), systolic and diastolic blood pressure values or BMI at any post-randomisation time point (Table 2).

Treadmill walk time improved in the intervention group. The difference at 12 and 24 weeks was 88 s (95\% CI 52-123, $P<0.001$, Hedges g $1.41,95 \%$ CI $0.76-2.05)$ and $69 \mathrm{~s}$ (95\% CI 33-105, $P<0.001$ ), respectively (Table 2 ).

Exercise behaviour scores from the Godin LSI were improved in the intervention group at all follow-up time points during the intervention with statistically significant differences at 6 and 12 


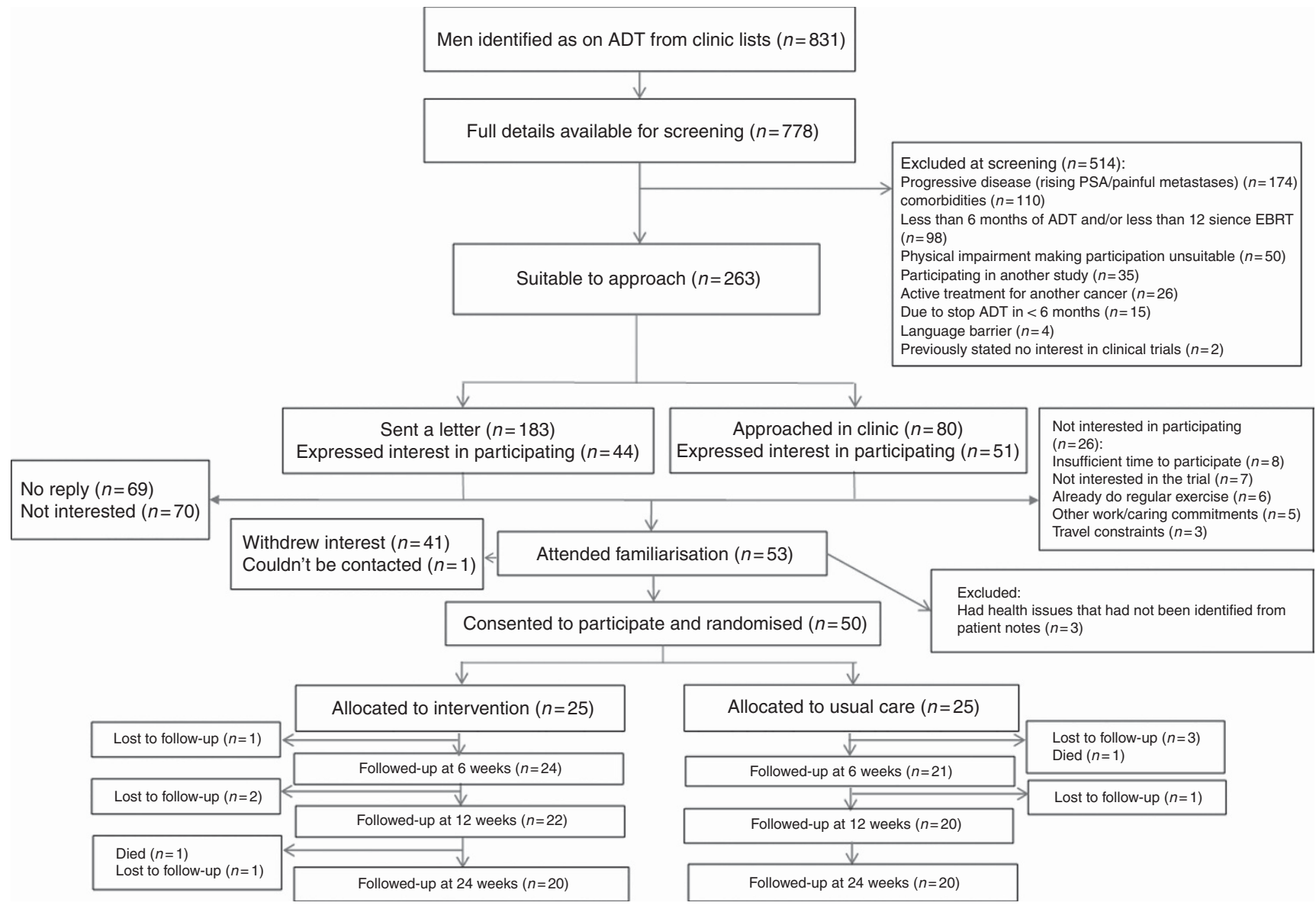

Figure 1. Consolidated Standards of Reporting Trials (CONSORT) flow diagram for final 50 participants recruited into the main trial.

weeks ( 6 weeks $P=0.02 ; 12$ weeks $P=0.05$ ). At 12 weeks, there was a moderate beneficial effect of the intervention of 0.57 s.d. (95\% CI -0.02 to 1.15$)$. There was no difference detected in exercise behaviour at 24 weeks $(P=0.58)$.

There were improvements in $D_{\text {peak }}$ for the FMD test, skeletal muscle mass (Table 3) and SHBG (Table 4) at 12 weeks. No meaningful change occurred in any other physiological measure or in any dietary outcomes (Supplementary Table 1).

\section{DISCUSSION}

At the end of the exercise intervention (12 weeks), a beneficial effect of the intervention on endothelial function occurred with an increased relative FMD of $2.2 \%$ (effect size of $>0.5$ s.d.). These differences between groups were not maintained 12 weeks after withdrawal of the intervention (Figure 2).

There is academic debate around how best to report relative FMD, with much of the earlier work using a simple ratio. Problems with these ratios have been identified (Tanner, 1949) and allometric scaling of ratio data for physiological measurements has been shown to be a more appropriate form of data analysis and presentation (Packard and Boardman, 1999; Curran-Everett, 2013). Such scaling more accurately accounts for variability in body and other anatomical sizes. Recently, Atkinson (2014) confirmed the appropriateness of allometric scaling for changes in arterial diameter in FMD analysis. In the current study, without such scaling, the difference in relative FMD expressed as a simple ratio is almost identical in magnitude $(2.3 \%)$ to the allometric-scaled value with a similar effect size (Table 2).
FMD has been widely associated with changes in cardiovascular health. An inverse relationship between relative FMD and the risk of future cardiovascular events (e.g., myocardial infarction and stroke) exists, with a meta-analysis suggesting reduced cardiovascular risk of $13 \%$ (95\% CI $8-17 \%$ ) per $1 \%$ higher relative FMD in individuals with any pre-existing cardiovascular risk factor (Ras et al, 2013). Although these findings have been developed from non-scaled data, reanalysis of the Multi Ethnic Study of Atherosclerosis indicated that allometric-scaled FMD is robust in the association with cardiovascular health outcomes (Atkinson and Batterham, 2013). Within the current study, $68 \%$ of the men had pre-existing evidence of cardiovascular disease (Table 1), but a diagnosis of prostate cancer in itself appears to be associated with increased cardiovascular risk: a comprehensive registry-based study from Sweden found that men diagnosed with prostate cancer appear to constitute a particularly high-risk group for cardiovascular events over matched controls without cancer, with treatment by ADT conferring additional risk (Van Hemelrijck et al, 2010). An estimated annual cardiovascular event rate of $\sim 14.2 \%$ in the Swedish PCBaSe study referred to above was reported in a recent meta-analysis (Bosco et al, 2015). Extrapolating from these data, one can tentatively estimate that, were the changes in FMD seen in this study translated to clinically significant risk reduction, 29\% fewer cardiovascular events would be encountered, providing an absolute risk reduction of $4.1 \%$. Otherwise stated, one would have to deliver the intervention to 24 men to prevent a single cardiovascular event per annum. As such, the results of the current study are suggestive of cardiovascular benefit of a 12-week exercise intervention in men on ADT, although further studies are required to correlate changes with cardiovascular outcomes. 
Table 1. Baseline characteristics of the participants by treatment group

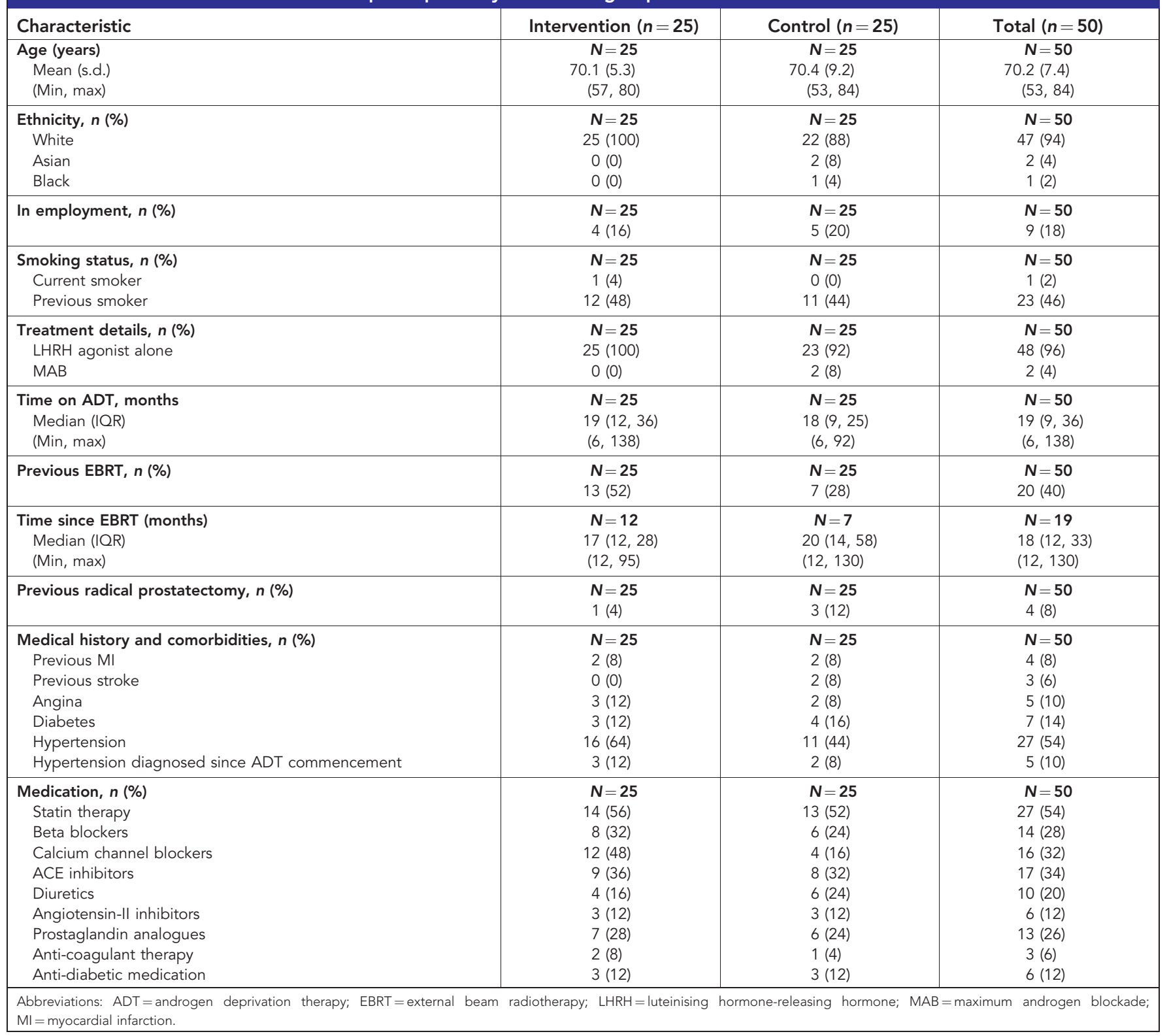

Several mechanisms could be responsible for the changes observed in FMD. Previous studies have demonstrated improvements in endothelial function with increased physical activity are only partly mediated by changes in traditional cardiovascular risk factors (Green et al, 2003). A direct effect of periods of increased shear stress on arterial walls during exercise can lead to increased nitric-oxide-dependent vascular dilatation (Tinken et al, 2010). Such an explanation could account for the observed changes in FMD, despite only small effects on other cardiovascular risk factors. Changes in SHBG at 12 weeks could be indicative of changes in insulin resistance between groups (Wallace et al, 2013), which could influence FMD (Suzuki et al, 2004). Although SHBG has been shown to increase after lifestyle interventions including exercise and diet in healthy adult males (Tymchuk et al, 1998) consistent with changes in insulin concentrations, the results of the current study could be interpreted as a deterioration in insulin sensitivity in the control group leading to a reduction in SHBG given the association between long-term ADT and increasing risk of developing type II diabetes (Alibhai et al, 2009). However, given the small sample size of the study, such an interpretation should be made with caution.
Previous evidence of improvements in cardiovascular health with exercise training in men established on ADT is limited. Recent studies have shown improvements in anthropometric and metabolic markers of cardiovascular risk with exercise training (Nobes et al, 2012; Cormie et al, 2015); however, in both studies participants started the intervention at the same time as commencing ADT and so whether such results could be achieved in men on long-term ADT remained unclear. Reductions in systolic and diastolic blood pressure were reported by Culos-Reed et al (2010) in men on long-term ADT who underwent a 16-week programme of home-based exercise; however, changes of a similar magnitude were also found in a non-exercising control group, resulting in no difference between groups over time. More positively, Galvao et al (2010) reported decreased concentrations of C-reactive protein after a 12 -week supervised exercise intervention, but this finding was not supported by evidence of benefits in any other markers of cardiovascular health. As such, our finding of an improvement in endothelial function provides the most encouraging evidence of cardiovascular benefits following a lifestyle intervention in men on long-term ADT. 
Table 2. Summary of outcome measures by treatment group

\begin{tabular}{|c|c|c|c|}
\hline Outcome & $\begin{array}{c}\text { Intervention } \\
(n=25) \\
\text { Raw mean (s.d.) }\end{array}$ & $\begin{array}{c}\text { Control } \\
(n=25) \\
\text { Raw mean } \\
\text { (s.d.) }\end{array}$ & $\begin{array}{c}\text { Adjusted mean } \\
\text { difference at } \\
12 \text { weeks }(95 \% \mathrm{Cl}) \\
P \text {-value } \\
\text { Effect size in s.d. } \\
(95 \% \mathrm{Cl})\end{array}$ \\
\hline \multicolumn{4}{|c|}{ Allometrically scaled relative FMD (\%) ${ }^{a}$} \\
\hline Baseline & $4.5(3.4)$ & $4.6(3.4)$ & \multirow{4}{*}{$\begin{array}{c}2.2(0.1,4.3) \\
P=0.04 \\
0.60(0.005,1.18)\end{array}$} \\
\hline Week 6 & $6.9(3.4)$ & $4.4(3.4)$ & \\
\hline Week 12 & $7.6(3.4)$ & $5.3(3.4)$ & \\
\hline Week 24 & $7.5(3.4)$ & $6.3(3.4)$ & \\
\hline \multicolumn{4}{|c|}{ Non-scaled relative FMD (\%) ${ }^{a}$} \\
\hline Baseline & $4.6(4.2)$ & $4.7(4.2)$ & \multirow{4}{*}{$\begin{array}{c}2.3(0.1,4.5) \\
P=0.04 \\
0.60(0.01,1.19)\end{array}$} \\
\hline Week 6 & $7.0(3.9)$ & $4.5(3.8)$ & \\
\hline Week 12 & $7.7(4.1)$ & $5.3(4.0)$ & \\
\hline Week 24 & $7.5(4.0)$ & $6.3(4.0)$ & \\
\hline \multicolumn{4}{|c|}{ Absolute FMD (mm) } \\
\hline Baseline & $0.23(0.18)$ & $0.22(0.11)$ & \multirow{4}{*}{$\begin{array}{c}0.11(0.00,0.23) \\
\quad P=0.05 \\
0.59(-0.01,1.17)\end{array}$} \\
\hline Week 6 & $0.35(0.22)$ & $0.23(0.20)$ & \\
\hline Week 12 & $0.37(0.20)$ & $0.25(0.15)$ & \\
\hline Week 24 & $0.37(0.18)$ & $0.30(0.16)$ & \\
\hline \multicolumn{4}{|c|}{ Allometrically scaled GTN-mediated dilatation (\%) ${ }^{a}$} \\
\hline Baseline & $12.3(4.2)$ & $11.9(4.2)$ & \multirow{4}{*}{$\begin{array}{c}0.6(-2.4,3.6) \\
P=0.71 \\
0.11(-0.47,0.68)\end{array}$} \\
\hline Week 6 & $11.2(4.2)$ & $14.6(4.2)$ & \\
\hline Week 12 & $11.5(4.2)$ & $10.9(4.2)$ & \\
\hline Week 24 & $13.4(4.2)$ & $11.3(4.2)$ & \\
\hline \multicolumn{4}{|c|}{ Non-scaled relative GTN-mediated dilatation (\%) } \\
\hline Baseline & $12.5(5.0)$ & $12.0(4.3)$ & \multirow{4}{*}{$\begin{array}{c}1.2(-2.2,4.7) \\
P=0.48 \\
0.21(-0.37,0.78)\end{array}$} \\
\hline Week 6 & $12.0(3.5)$ & $14.6(6.3)$ & \\
\hline Week 12 & $12.2(5.5)$ & $10.4(4.5)$ & \\
\hline Week 24 & $13.9(4.5)$ & $11.0(4.9)$ & \\
\hline \multicolumn{4}{|c|}{ Absolute GTN-mediated dilatation (mm) } \\
\hline Baseline & $0.62(0.25)$ & $0.59(0.20)$ & \multirow{4}{*}{$\begin{array}{c}0.04(-0.13,0.20) \\
P=0.66 \\
0.13(-0.45,0.70)\end{array}$} \\
\hline Week 6 & $0.57(0.15)$ & $0.74(0.31)$ & \\
\hline Week 12 & $0.58(0.27)$ & $0.52(0.21)$ & \\
\hline Week 24 & $0.67,(0.22)$ & $0.55(0.24)$ & \\
\hline \multicolumn{4}{|c|}{ Systolic blood pressure $(\mathrm{mm} \mathrm{Hg})$} \\
\hline Baseline & $144(18)$ & $145(20)$ & \multirow{4}{*}{$\begin{array}{c}-7.0(-16.1,2.2) \\
P=0.14 \\
0.44(-0.15,1.02)\end{array}$} \\
\hline Week 6 & $137(14)$ & 147 (19) & \\
\hline Week 12 & $138(20)$ & $145(20)$ & \\
\hline Week 24 & $139(19)$ & $141(23)$ & \\
\hline \multicolumn{4}{|c|}{ Diastolic blood pressure $(\mathrm{mm} \mathrm{Hg})$} \\
\hline Baseline & $80(8)$ & $76(8)$ & \multirow{4}{*}{$\begin{array}{c}-3.3(-7.0,0.4) \\
P=0.08 \\
0.50(-0.09,1.08)\end{array}$} \\
\hline Week 6 & 77 (9) & $76(7)$ & \\
\hline Week 12 & $76(10)$ & $76(7)$ & \\
\hline Week 24 & $77(11)$ & $75(8)$ & \\
\hline \multicolumn{4}{|c|}{ BMI $\left(\mathrm{kg} / \mathrm{m}^{2}\right)$} \\
\hline Baseline & $30.6(5.0)$ & $28.8(5.2)$ & \multirow{4}{*}{$\begin{array}{c}0.1(-0.5,0.6) \\
P=0.74 \\
-0.10(-0.67,0.48)\end{array}$} \\
\hline Week 6 & $30.3(5.0)$ & $28.4(3.2)$ & \\
\hline Week 12 & $29.8(4.8)$ & $29.0(4.8)$ & \\
\hline Week 24 & $28.9(2.8)$ & $29.0(4.8)$ & \\
\hline \multicolumn{4}{|c|}{ Treadmill walk time (s) } \\
\hline Baseline & $344(144)$ & $346(162)$ & $87.6(52.0,123.3)$ \\
\hline Week 6 & $420(143)$ & $411(134)$ & $P<0.001$ \\
\hline Week 12 & 435 (133) & $389(115)$ & $1.41(0.76,2.05)$ \\
\hline Week 24 & $447(131)$ & $400(121)$ & \\
\hline Godin LSI & & & \\
\hline Baseline & $20.5(13.2)$ & $20.7(17.3)$ & $12.5(-0.1,25.0)$ \\
\hline Week 6 & $31.0(17.8)$ & $22.4(22.0)$ & $P=0.05$ \\
\hline Week 12 & 38.4 (27.2) & $26.2(21.1)$ & $0.57(-0.02,1.15)$ \\
\hline Week 24 & $36.5(27.5)$ & $31.4(30.4)$ & \\
\hline $\begin{array}{l}\text { Abbreviations } \\
\text { trinitrate; BMI } \\
{ }^{\text {a } A d j u s t e d ~ ' c o ~}\end{array}$ & confidence interval; & $\begin{array}{l}=\text { Flow-media } \\
\text { ure Score Index } \\
\text { n. }\end{array}$ & dilatation; GTN = Glycery \\
\hline
\end{tabular}

Table 3. Summary of secondary outcome measures by treatment group

\begin{tabular}{|c|c|c|c|}
\hline Outcome & $\begin{array}{c}\text { Intervention } \\
(n=25) \\
\text { Raw mean (s.d.) }\end{array}$ & $\begin{array}{c}\text { Control } \\
(n=25) \\
\text { Raw mean (s.d.) }\end{array}$ & $\begin{array}{c}\text { Adjusted mean } \\
\text { difference at } \\
12 \text { weeks } \\
(95 \% \mathrm{Cl}) \\
P \text {-value }\end{array}$ \\
\hline \multicolumn{4}{|c|}{ FMD $D_{\text {rest }}(\mathrm{mm})$} \\
\hline $\begin{array}{l}\text { Baseline } \\
\text { Week } 6 \\
\text { Week } 12 \\
\text { Week } 24\end{array}$ & $\begin{array}{l}4.9(0.6) \\
5.0(0.8) \\
5.0(0.5) \\
4.9(0.6)\end{array}$ & $\begin{array}{l}4.8(0.5) \\
5.0(0.6) \\
4.8(0.5) \\
4.8(0.6)\end{array}$ & $\begin{array}{c}0.1(-0.1,0.3) \\
P=0.27\end{array}$ \\
\hline \multicolumn{4}{|c|}{ FMD $D_{\text {peak }}(\mathrm{mm})$} \\
\hline $\begin{array}{l}\text { Baseline } \\
\text { Week } 6 \\
\text { Week } 12 \\
\text { Week } 24\end{array}$ & $\begin{array}{l}5.1(0.7) \\
5.3(0.9) \\
5.3(0.5) \\
5.3(0.6)\end{array}$ & $\begin{array}{l}5.0(0.6) \\
5.2(0.7) \\
5.1(0.5) \\
5.1(0.6)\end{array}$ & $\begin{array}{c}0.2(0.0,0.5) \\
P=0.04\end{array}$ \\
\hline \multicolumn{4}{|c|}{ GTN $D_{\text {rest }}(\mathrm{mm})$} \\
\hline $\begin{array}{l}\text { Baseline } \\
\text { Week } 6 \\
\text { Week } 12 \\
\text { Week } 24\end{array}$ & $\begin{array}{l}5.0(0.5) \\
4.8(0.6) \\
4.9(0.5) \\
4.9(0.4)\end{array}$ & $\begin{array}{l}5.0(0.6) \\
5.2(0.6) \\
5.2(0.6) \\
5.1(0.6)\end{array}$ & $\begin{array}{c}-0.2(-0.6,0.1) \\
P=0.12\end{array}$ \\
\hline \multicolumn{4}{|c|}{ GTN $D_{\text {peak }}(\mathrm{mm})$} \\
\hline $\begin{array}{l}\text { Baseline } \\
\text { Week } 6 \\
\text { Week } 12 \\
\text { Week } 24\end{array}$ & $\begin{array}{l}5.6(0.6) \\
5.4(0.6) \\
5.5(0.6) \\
5.6(0.5)\end{array}$ & $\begin{array}{l}5.6(0.7) \\
5.9(0.6) \\
5.7(0.6) \\
5.6(0.6)\end{array}$ & $\begin{array}{c}-0.2(-0.6,0.1) \\
P=0.18\end{array}$ \\
\hline \multicolumn{4}{|c|}{ Body fat mass $(\mathrm{kg})$} \\
\hline $\begin{array}{l}\text { Baseline } \\
\text { Week } 6 \\
\text { Week } 12 \\
\text { Week } 24\end{array}$ & $\begin{array}{l}34.5(11.6) \\
32.9(11.2) \\
31.6(10.9) \\
29.9(7.1)\end{array}$ & $\begin{array}{l}30.4(11.5) \\
27.9(7.4) \\
29.6(10.9) \\
29.0(11.1)\end{array}$ & $\begin{array}{c}-0.7(-2.2,0.7) \\
P=0.32\end{array}$ \\
\hline \multicolumn{4}{|c|}{ Skeletal muscle mass $(\mathrm{kg})$} \\
\hline $\begin{array}{l}\text { Baseline } \\
\text { Week } 6 \\
\text { Week } 12 \\
\text { Week } 24\end{array}$ & $\begin{array}{l}31.9(4.2) \\
32.3(4.6) \\
32.9(4.6) \\
32.7(4.0) \\
\end{array}$ & $\begin{array}{l}31.2(5.7) \\
31.6(6.0) \\
32.3(5.5) \\
32.6(5.7)\end{array}$ & $\begin{array}{c}0.6(0.1,1.1) \\
P=0.03\end{array}$ \\
\hline
\end{tabular}

Statistically significant changes in skeletal muscle were observed over the duration of the intervention. These findings support evidence that lifestyle interventions can reverse the decrease in lean body mass experienced by men treated with ADT (Galvao et al, 2010; Galvão et al, 2014). The largest effect of the intervention was seen in treadmill walk time however. Although improvements from baseline walking distance was seen in the control group this did not match the magnitude of improvements in the intervention group. This evidence demonstrates exercise training can reduce the decline in physical function observed with ADT (Alibhai et al, 2010).

Evidence of an increase in exercise behaviour and exercise tolerance in the control group is one limitation of the current study. Although similar changes in exercise behaviour have previously been reported in cancer patients randomised to a control group of an exercise study (Courneya et al, 2004), such findings could have a confounding effect on overall conclusions.

A further limitation of this study is that improvements in a number of outcome measures seen at endpoint assessments in the intervention group were lost following withdrawal of supervision. Conducting follow-up assessments after a lifestyle intervention has previously been undertaken by one study that reported a similar pattern of changes (Bourke et al, 2011). Designing effective lifestyle interventions for this population that can maintain benefits after removal of supervision is clearly an area in which further investigations are warranted. 
Table 4. Summary of lipid profile and blood marker measures by treatment group

\begin{tabular}{|c|c|c|c|}
\hline Outcome & $\begin{array}{l}\text { Intervention } \\
(n=25) \\
\text { Raw mean } \\
\text { (s.d.) }\end{array}$ & $\begin{array}{c}\text { Control } \\
(n=25) \\
\text { Raw mean } \\
\text { (s.d.) }\end{array}$ & $\begin{array}{c}\text { Adjusted mean } \\
\text { difference at } \\
12 \text { weeks } \\
(95 \% \mathrm{Cl}) \\
P \text {-value }\end{array}$ \\
\hline \multicolumn{4}{|l|}{ Lipid profile } \\
\hline $\begin{array}{l}\text { Total cholesterol } \\
\left(\mathrm{mmoll} \mathrm{I}^{-1}\right) \\
\text { Baseline } \\
\text { Week } 12\end{array}$ & $\begin{array}{l}5.0(1.2) \\
4.9(1.1)\end{array}$ & $\begin{array}{l}4.7(0.9) \\
4.8(0.8)\end{array}$ & $\begin{array}{c}-0.0(-0.3,0.3) \\
P=0.83\end{array}$ \\
\hline $\begin{array}{l}\text { HDL-C }\left(\mathrm{mmoll}^{-1}\right) \\
\text { Baseline } \\
\text { Week } 12\end{array}$ & $\begin{array}{l}1.4(0.4) \\
1.4(0.4)\end{array}$ & $\begin{array}{l}1.5(0.5) \\
1.5(0.5)\end{array}$ & $\begin{array}{c}0.0(-0.1,0.1) \\
P=0.60\end{array}$ \\
\hline $\begin{array}{l}\text { LDL-C }\left(\mathrm{mmol} \mathrm{I}^{-1}\right) \\
\text { Baseline } \\
\text { Week } 12\end{array}$ & $\begin{array}{l}2.7(1.1) \\
2.8(1.0)\end{array}$ & $\begin{array}{l}2.4(0.8) \\
2.6(0.8)\end{array}$ & $\begin{array}{c}-0.0(-0.3,0.2) \\
P=0.79\end{array}$ \\
\hline $\begin{array}{l}\text { Triglycerides } \\
\left(\mathrm{mmolI}^{-1}\right) \\
\text { Baseline } \\
\text { Week } 12\end{array}$ & $\begin{array}{l}1.9(0.7) \\
1.6(0.7)\end{array}$ & $\begin{array}{l}1.7(1.0) \\
1.6(0.8)\end{array}$ & $\begin{array}{c}-0.1(-0.3,0.2) \\
P=0.51\end{array}$ \\
\hline \multicolumn{4}{|l|}{ Blood markers } \\
\hline $\begin{array}{l}\text { Total testosterone } \\
\left(\mathrm{nmol} \mathrm{I}^{-1}\right) \\
\text { Baseline } \\
\text { Week } 12\end{array}$ & $\begin{array}{l}0.5(0.2) \\
0.4(0.1)\end{array}$ & $\begin{array}{l}0.5(0.2) \\
0.4(0.2)\end{array}$ & $\begin{array}{c}-0.0(-0.1,0.0) \\
P=0.43\end{array}$ \\
\hline $\begin{array}{l}\text { SHBG }\left(\mathrm{nmol} \mathrm{I}^{-1}\right) \\
\text { Baseline } \\
\text { Week } 12\end{array}$ & $\begin{array}{l}54.0(33.0) \\
54.6(23.8)\end{array}$ & $\begin{array}{l}56.9(31.6) \\
51.0(30.2)\end{array}$ & $\begin{array}{c}5.8(0.8,10.9) \\
P=0.03\end{array}$ \\
\hline $\begin{array}{l}\text { Free androgen index } \\
\text { Baseline } \\
\text { Week } 12\end{array}$ & $\begin{array}{l}1.2(0.8) \\
1.0(0.5)\end{array}$ & $\begin{array}{l}1.2(1.0) \\
1.3(1.1)\end{array}$ & $\begin{array}{c}-0.2(-0.5,0.1) \\
P=0.17\end{array}$ \\
\hline $\begin{array}{l}\text { Prostate-specific } \\
\text { antigen }\left(\mathrm{ng} \mathrm{ml}^{-1}\right) \\
\text { Baseline } \\
\text { Week } 12\end{array}$ & $\begin{array}{l}2.1(4.8) \\
3.7(8.7)\end{array}$ & $\begin{array}{l}1.5(2.7) \\
2.3(4.5)\end{array}$ & $\begin{array}{c}0.1 .(-1.0,1.3) \\
P=0.80\end{array}$ \\
\hline
\end{tabular}

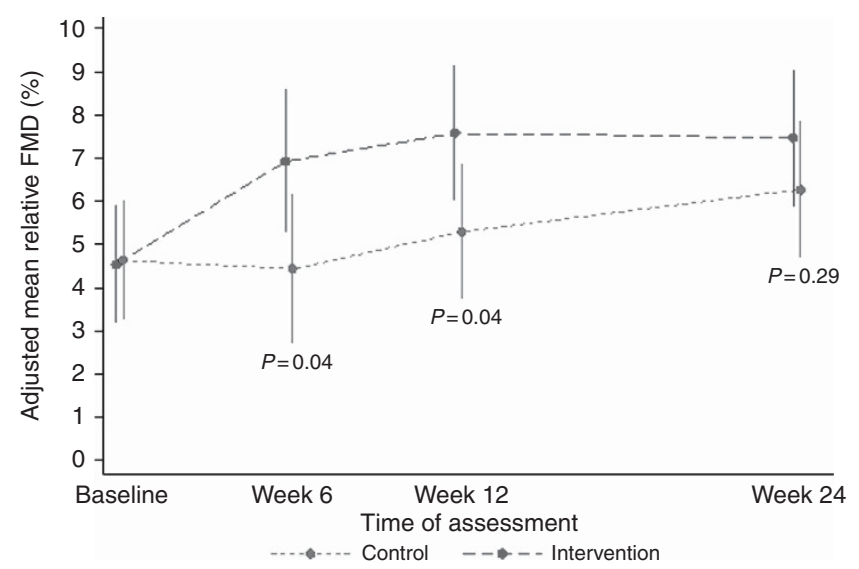

Figure 2. Allometrically-scaled, adjusted mean relative FMD by treatment group at all time points, with $95 \%$ confidence intervals and $P$-values.

Finally, the controlled recruitment of men into this study could limit generalisability of the findings. As part of the first study to report an exercise-based intervention in men with metastatic prostate cancer (Bourke et al, 2011, 2014), the necessity to maintain rigour and ensure patient safety resulted in the exclusion of $67 \%$ of men identified as being treated with ADT. Comparison of this exclusion rate against other studies is difficult due to variations in the detail of recruitment statistics reported; however, the study establishes the principle that such lifestyle interventions are feasible in this population, an important consideration for future studies.

In conclusion, our findings demonstrate evidence of improvements in endothelial function after a lifestyle intervention including supervised exercise training and dietary advice in men on long-term ADT for prostate cancer that were not maintained following withdrawal of the intervention. Larger studies are required to investigate any impact on clinically relevant cardiovascular outcomes, as well as the value of a longer supervised intervention.

\section{ACKNOWLEDGEMENTS}

We thank the volunteers for participating in the study and the technical staff at Sheffield Hallam University for their assistance in conducting assessments. This study was funded in full by Sheffield Hallam University.

\section{CONFLICT OF INTEREST}

The authors declare no conflict of interest.

\section{REFERENCES}

Alibhai SM, Breunis H, Timilshina N, Johnston C, Tomlinson G, Tannock I, Krahn M, Fleshner NE, Warde P, Canning SD, Klotz L, Naglie G (2010) Impact of androgen-deprivation therapy on physical function and quality of life in men with nonmetastatic prostate cancer. J Clin Oncol 28: 5038-5045.

Alibhai SM, Duong-Hua M, Sutradhar R, Fleshner NE, Warde P, Cheung AM, Paszat LF (2009) Impact of androgen deprivation therapy on cardiovascular disease and diabetes. J Clin Oncol 27: 3452-3458.

Atkinson G (2014) Shear rate normalization is not essential for removing the dependency of flow-mediated dilation on baseline artery diameter: past research revisited. Physiol Meas 35: 1825-1835.

Atkinson G, Batterham AM (2013) The percentage flow-mediated dilation index: a large-sample investigation of its appropriateness, potential for bias and causal nexus in vascular medicine. Vasc Med 18: 354-365.

Atkinson G, Batterham AM, Thijssen DH, Green DJ (2013) A new approach to improve the specificity of flow-mediated dilation for indicating endothelial function in cardiovascular research. J Hypertens 31: 287-291.

Black MA, Cable NT, Thijssen DH, Green DJ (2008) Importance of measuring the time course of flow-mediated dilatation in humans. Hypertension 51: 203-210.

Borg GA (1982) Psychophysical bases of perceived exertion. Med Sci Sports Exerc 14: 377-381.

Bosco C, Bosnyak Z, Malmberg A, Adolfsson J, Keating NL, Van Hemelrijck M (2015) Quantifying observational evidence for risk of fatal and nonfatal cardiovascular disease following androgen deprivation therapy for prostate cancer: a meta-analysis. Eur Urol 68: 386-396.

Bourke L, Gilbert S, Hooper R, Steed LA, Joshi M, Catto JW, Saxton JM, Rosario DJ (2014) Lifestyle changes for improving disease-specific quality of life in sedentary men on long-term androgen-deprivation therapy for advanced prostate cancer: a randomised controlled trial. Eur Urol 65: 865-872.

Bourke L, Doll H, Crank H, Daley A, Rosario D, Saxton JM (2011) Lifestyle intervention in men with advanced prostate cancer receiving androgen suppression therapy: a feasibility study. Cancer Epidemiol Biomarkers Prev 20: $647-657$.

Brown H, Prescott R (2006) Applied Mixed Models in Medicine. John Wiley \& Sons: Chichester, West Sussex, UK.

Celermajer DS (1997) Endothelial dysfunction: does it matter? Is it reversible? J Am Coll Cardiol 30: 325-333. 
Cormie P, Galvão D, Spry N, Joseph D, Chee R, Taaffe D, Chambers SK, Newton R (2015) Can supervised exercise prevent treatment toxicity in prostate cancer patients initiating androgen deprivation therapy: a randomised controlled trial. BJU Int 115: 256-266.

Corretti MC, Anderson TJ, Benjamin EJ, Celermajer D, Charbonneau F, Creager MA, Deanfield J, Drexler H, Gerhard-Herman M, Herrington D (2002) Guidelines for the ultrasound assessment of endothelial-dependent flow-mediated vasodilation of the brachial artery: a report of the International Brachial Artery Reactivity Task Force. J Am Coll Cardiol 39: 257-265.

Courneya KS, Friedenreich CM, Quinney HA, Fields AL, Jones LW, Fairey AS (2004) Predictors of adherence and contamination in a randomized trial of exercise in colorectal cancer survivors. Psychooncology 13: $857-866$.

Culos-Reed SN, Robinson JW, Lau H, Stephenson L, Keats M, Norris S, Kline G, Faris P (2010) Physical activity for men receiving androgen deprivation therapy for prostate cancer: benefits from a 16-week intervention. Support Care Cancer 18: 591-599.

Curran-Everett D (2013) Explorations in statistics: the analysis of ratios and normalized data. Adv Physiol Educ 37: 213-219.

Deanfield JE, Halcox JP, Rabelink TJ (2007) Endothelial function and dysfunction: testing and clinical relevance. Circulation 115: 1285-1295.

Edwards DG, Schofield RS, Lennon SL, Pierce GL, Nichols WW, Braith RW (2004) Effect of exercise training on endothelial function in men with coronary artery disease. Am J Cardiol 93: 617-620.

Galvao DA, Taaffe DR, Spry N, Joseph D, Newton RU (2010) Combined resistance and aerobic exercise program reverses muscle loss in men undergoing androgen suppression therapy for prostate cancer without bone metastases: a randomized controlled trial. J Clin Oncol 28: 340-347.

Galvão DA, Spry N, Denham J, Taaffe DR, Cormie P, Joseph D, Lamb DS, Chambers SK, Newton RU (2014) A multicentre year-long randomised controlled trial of exercise training targeting physical functioning in men with prostate cancer previously treated with androgen suppression and radiation from TROG 03.04 RADAR. Eur Urol 65: 856-864.

Gilbert SE, Tew GA, Bourke L, Winter EM, Rosario DJ (2013) Assessment of endothelial dysfunction by flow-mediated dilatation in men on long-term androgen deprivation therapy for prostate cancer. Exp Physiol 98: 1401-1410.

Godin G, Shephard RJ (1985) A simple method to assess exercise behavior in the community. Can J Appl Sport Sci 10: 141-146.

Gokce N, Vita JA, Bader DS, Sherman DL, Hunter LM, Holbrook M, O'Malley C, Keaney Jr JF, Balady GJ (2002) Effect of exercise on upper and lower extremity endothelial function in patients with coronary artery disease. Am J Cardiol 90: 124-127.

Green DJ, Jones H, Thijssen D, Cable NT, Atkinson G (2011) Flow-mediated dilation and cardiovascular event prediction: does nitric oxide matter? Hypertension 57: 363-369.

Green DJ, Walsh JH, Maiorana A, Best MJ, Taylor RR, O’Driscoll JG (2003) Exercise-induced improvement in endothelial dysfunction is not mediated by changes in $\mathrm{CV}$ risk factors: pooled analysis of diverse patient populations. Am J Physiol Heart Circ Physiol 285: H2679-H2687.

Harville DA (1977) Maximum likelihood approaches to variance component estimation and to related problems. J Am Stat Assoc 72: 320-338.
Kaminsky LA, Whaley MH (1998) Evaluation of a new standardized ramp protocol: the BSU/Bruce Ramp protocol. J Cardiopulm Rehabil Prev 18: 438-444.

Nguyen PL, Alibhai SM, Basaria S, D'Amico AV, Kantoff PW, Keating NL, Penson DF, Rosario DJ, Tombal B, Smith MR (2015) Adverse effects of androgen deprivation therapy and strategies to mitigate them. Eur Urol 67: 825-836.

Nobes JP, Langley SE, Klopper T, Russell-Jones D, Laing RW (2012) A prospective, randomized pilot study evaluating the effects of metformin and lifestyle intervention on patients with prostate cancer receiving androgen deprivation therapy. BJU Int 109: 1495-1502.

Packard GC, Boardman TJ (1999) The use of percentages and size-specific indices to normalize physiological data for variation in body size: wasted time, wasted effort? Comp Biochem Physiol A Mol Integr Physiol 122: 37-44.

Parker BA, Trehearn TL, Meendering JR (2009) Pick your Poiseuille: normalizing the shear stimulus in studies of flow-mediated dilation. J Appl Physiol 107: 1357-1359.

Ras RT, Streppel MT, Draijer R, Zock PL (2013) Flow-mediated dilation and cardiovascular risk prediction: a systematic review with meta-analysis. Int J Cardiol 168: 344-351.

Rippe JM, Angelopoulos TJ (2014) Lifestyle strategies for cardiovascular risk reduction. Curr Atheroscler Rep 16: 1-7.

Schubert M, Joniau S, Gontero P, Kneitz S, Scholz C, Kneitz B, Briganti A, Karnes RJ, Tombal B, Walz J (2012) The role of adjuvant hormonal treatment after surgery for localized high-risk prostate cancer: results of a matched multiinstitutional analysis. Adv Urol 2012: 612707.

Suzuki M, Takamisawa I, Suzuki K, Hiuge A, Horio T, Yoshimasa Y, Harano Y (2004) Close association of endothelial dysfunction with insulin resistance and carotid wall thickening in hypertension. Am J Hypertens 17: 228-232.

Tanner JM (1949) Fallacy of per-weight and per-surface area standards, and their relation to spurious correlation. J Appl Physiol 2: 1-15.

Tinken TM, Thijssen DH, Hopkins N, Dawson EA, Cable NT, Green DJ (2010) Shear stress mediates endothelial adaptations to exercise training in humans. Hypertension 55: 312-318.

Tymchuk CN, Tessler SB, Aronson WJ, Barnard RJ (1998) Effects of diet and exercise on insulin, sex hormone-binding globulin, and prostate-specific antigen. Nutr Cancer 31: 127-131.

Van Hemelrijck M, Garmo H, Holmberg L, Ingelsson E, Bratt O, Bill-Axelson A, Lambe M, Stattin P, Adolfsson J (2010) Absolute and relative risk of cardiovascular disease in men with prostate cancer: results from the Population-Based PCBaSe Sweden. J Clin Oncol 28: 3448-3456.

Wallace IR, McKinley MC, Bell PM, Hunter SJ (2013) Sex hormone binding globulin and insulin resistance. Clin Endocrinol (Oxf) 78: 321-329.

Zhao J, Zhu S, Sun L, Meng F, Zhao L, Zhao Y, Tian H, Li P, Niu Y (2014) Androgen deprivation therapy for prostate cancer is associated with cardiovascular morbidity and mortality: a meta-analysis of populationbased observational studies. PLoS One 9: e107516.

This work is published under the standard license to publish agreement. After 12 months the work will become freely available and the license terms will switch to a Creative Commons AttributionNonCommercial-Share Alike 4.0 Unported License.

Supplementary Information accompanies this paper on British Journal of Cancer website (http://www.nature.com/bjc) 